\title{
Gly972Arg variant in the insulin receptor substrate-1 gene and association with Type 2 diabetes: a meta-analysis of $\mathbf{2 7}$ studies
}

\author{
A. Jellema ${ }^{1,2}$, M. P. A. Zeegers ${ }^{3}$, E. J. M. Feskens' ${ }^{1}$, P. C. Dagnelie ${ }^{3}$, R. P. Mensink ${ }^{2}$ \\ ${ }^{1}$ Centre for Nutrition and Health, National Institute for Public Health and the Environment, Bilthoven, The Netherlands \\ 2 Department of Human Biology, Maastricht University, Maastricht, The Netherlands \\ ${ }^{3}$ Department of Epidemiology, Maastricht University, Maastricht, The Netherlands
}

\begin{abstract}
Aims/hypothesis. Several case-control studies have examined the association between the Gly972Arg variant in the IRS-1 gene and Type 2 diabetes, but most had limited power and results could therefore be conflicting.

Methods. We systematically reviewed the literature by means of a meta-analysis and investigated sources of heterogeneity in results of different studies.

Results. The summary risk ratio, based on 3408 cases and 5419 control cases from 27 studies, was 1.25 (95\% CI 1.05-1.48). The results, however, differed according to the type of study, method of verifying non-diabetic status of the control subjects, and age of the case subjects. Population-based studies reported
\end{abstract}

Insulin receptor substrate-1 (IRS-1) is the first substrate of the insulin receptor in the insulin signalling pathway [1]. Due to this central role, the IRS-1 function could be related to the development of Type 2 diabetes. Polymorphisms in the IRS-1 gene were identified for the first time in 1993 [2]. Since then, many case control studies have examined the association between the Gly972Arg variant and Type 2 diabetes [2, $3,4,5,6,7,8,9,10,11,12,13,14,15,16,17,18,19$, $20,21,22,23,24,25,26]$. Results, however, are not

Received: 19 December 2002 / Revised: 10 February 2003

Published online: 18 June 2003

C) Springer-Verlag 2003

Corresponding author: Dr. A. Jellema, Department of Human Biology, Maastricht University, P.O. Box 616, 6200 MD Maastricht, The Netherlands

E-mail: a.jellema@hb.unimaas.nl

Abbreviations: IRS-1, insulin receptor substrate-1; GTT, glucose tolerance test. lower odds ratios than hospital-based studies (OR $0.98,95 \%$ CI $0.74-1.30$ vs OR $1.43,95 \%$ CI 1.17-1.74). Also, the diagnostic test to exclude diabetes amongst control subjects interacted with the association between the IRS-1 Gly972Arg variant and Type 2 diabetes $(p=0.03)$. Finally, the odds ratio reduced with increasing age $(p=0.03)$.

Conclusion/interpretation. Overall, carriers of the $972 \mathrm{Arg}$ variant of the IRS-1 gene are at a $25 \%$ increased risk of having Type 2 diabetes compared with non-carriers. The odds ratios are generally higher in hospital-based studies, including relatively young, symptomatic, cases. [Diabetologia (2003) 46:990-995]

Keywords IRS-1, Gly972Arg, obesity, Type 2 diabetes, meta-analysis.

consistent. It has been noticed that the heterozygous variant of the Gly972Arg polymorphism occurred more frequently in Type 2 diabetic subjects compared to control subjects (19\% vs 7\%) [2]. Based on seven studies published up to 1996 [2, 3, 4, 5, 8, 12], a combined odds ratio of 1.49 has been reported [12]. However, since then a number of other studies have been published in which no association was observed [15, $16,17,19,20,21,22,23]$. Besides study power and other methodological issues, interaction with important diabetic risk factors such as body weight could have resulted in heterogeneous findings. Indeed, an association between the Arg-variant and insulin resistance in obese but not in lean subjects has been observed [27]. It has been suggested that excess body weight positively interacts with the Arg-variant thereby increasing the Type 2 diabetes risk [12].

The aim of our study was therefore to review the literature systematically by means of a meta-analysis, and to provide a quantitative summary estimate on the 


$\begin{array}{lllll}\text { Ref } & \text { Author } & \text { Year } & \text { Ethnicity } & \text { Test } \\ & & & & \\ 2 & \text { Almind } & 1993 & \text { Cauc } & \text { fasting } \\ 3 & \text { Hager } & 1993 & \text { Cauc } & \text { fasting } \\ 4 & \text { Imai } & 1994 & \text { Cauc } & \text { no test } \\ 5 & \text { Laaks 1994 } & \text { Cauc } & \text { GTT } & \text { yes } \\ 6 & \text { Shimokawa } & 1994 & \text { Asian } & \text { GTT } \\ 8 & \text { Hitman } & 1995 & \text { Asian } & \text { fasting } \\ 8 & \text { Hitman } & 1995 & \text { Cauc } & \text { GTT } \\ 9 & \text { Mori } & 1995 & \text { Asian } & \text { GTT } \\ 10 & \text { Chuang } & 1996 & \text { Asian } & \text { GTT } \\ 11 & \text { Marrmarella } & 1996 & \text { Cauc } & \text {. } \\ 12 & \text { Sigal } & 1996 & \text { Cauc } & \text { no test } \\ 13 & \text { Ura } & 1996 & \text { Asian } & \text { no test } \\ 14 & \text { Zhang } & 1996 & \text { Cauc } & \text { fasting } \\ 15 & \text { Panz } & 1997 & \text { Cauc } & \text { no test } \\ 15 & \text { Panz } & 1997 & \text { Black } & \text { no test } \\ 16 & \text { Lepretre } & 1998 & \text { Asian } & \text { GTT } \\ 17 & \text { Yamada } & 1998 & \text { Asian } & \text { GTT } \\ 17 & \text { Yamada } & 1998 & \text { Asian } & \text { GTT } \\ 18 & \text { Baroni } & 1999 & \text { Cauc } & \text { fasting } \\ 19 & \text { t Hart } & 1999 & \text { Cauc } & \text { fasting } \\ 19 & \text { t Hart } & 1999 & \text { Cauc } & \text { fasting } \\ 20 & \text { Ito } & 1999 & \text { Cauc } & \text { fasting } \\ 21 & \text { Lei } & 1999 & \text { Black } & \text { fasting } \\ 22 & \text { Benecke } & 2000 & \text { Cauc } & \text { fasting } \\ 23 & \text { Celi } & 2000 & \text { S. Amer. } & \text { GTT } \\ 23 & \text { Celi } & 2000 & \text { Cauc } & \text { no test } \\ 26 & \text { Rosskopf } & 2000 & \text { Cauc } & \text { no } \\ & \text { Swumary } & \text { oddls 1atio } & & \\ & & & & \end{array}$

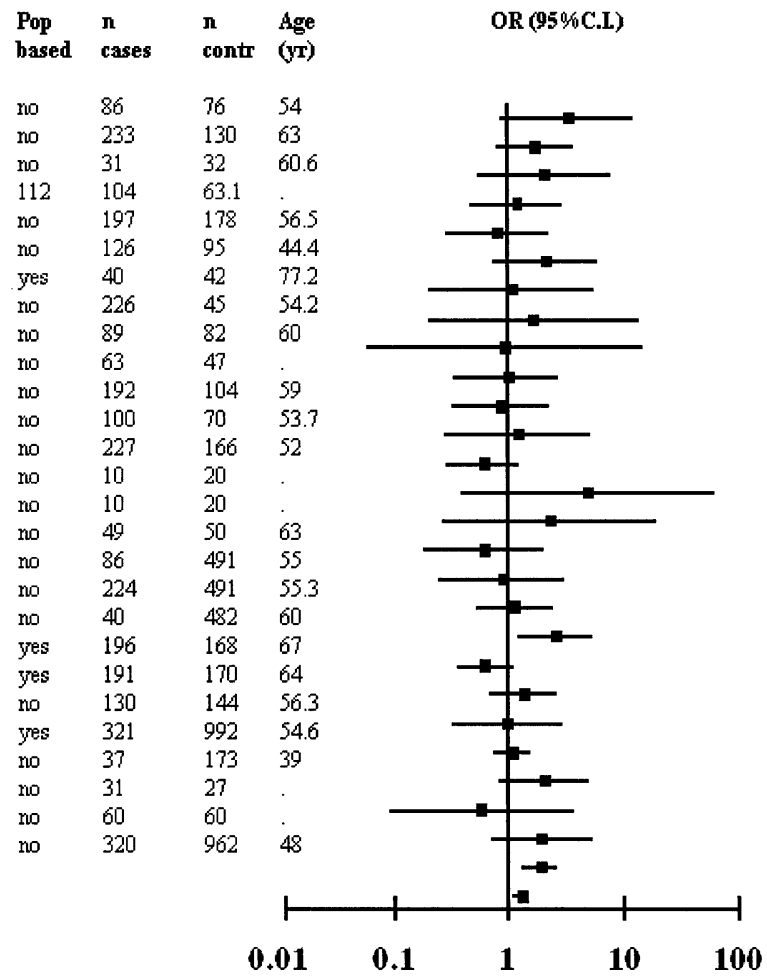

Fig. 1. Study characteristics and odds ratios of published articles concerning the effect of the Gly972Arg variant on the prevalence of Type 2 diabetes

association between the Gly972Arg variant in the IRS- 1 gene and the prevalence of Type 2 diabetes. In addition, sources of heterogeneity between studies were examined.

\section{Subjects and methods}

Search strategy. Studies were identified through a computerized Medline, Current Contents and Science Citation Index search on studies published until January 2002 using the free text words: diabetes, insulin receptor substrate, IRS-1, genotype, variant, Gly972Arg, and polymorphism. References in relevant publications were also examined. There were no language restrictions. For inclusion in this analysis, the publications had to give information about the prevalence of the Gly972Arg polymorphism in Type 2 diabetes patients and healthy non-familial control subjects. Another prerequisite was that sufficient data was given to calculate odds ratios. All investigations analysed in this meta-analysis have been carried out in accordance with the Declaration of Helsinki.

Data collection. For each study, information was collected concerning the characteristics of the subjects (age, sex, BMI, ethnicity, age of diagnosis), technique of the polymorphism (single strand conformation polymorphism analysis (SSCP) or direct enzyme digestion), type of study (hospital-based or population-based), and the diagnostic test used to exclude diabetes in control subjects (glucose tolerance test, fasting blood glucose measurement or no laboratory measurement). These study characteristics were used to evaluate sources of variation in effect estimates. All articles were independently scored by three

reviewers (AJ, MZ, EF) similar to an earlier approach [28]. Disagreements were solved in consensus meetings. Assuming a dominant model of inheritance, homozygous mutants were combined with the heterozygous group. Unadjusted odds ratios were calculated using $2 \times 2$ contingency tables for each study, based on the Gly972Arg variant (wild-type vs heterozygous and homozygous mutant) and prevalence of Type 2 diabetes (present vs not present).

Authors of all publications were approached for additional information about the BMI of the subjects, high BMI (BMI $\left.>27 \mathrm{~kg} / \mathrm{m}^{2}\right)$ or low BMI $\left(\mathrm{BMI} \leq 27 \mathrm{~kg} / \mathrm{m}^{2}\right)$. This additional information was provided by nine authors on ten study populations $[8,13,15,16,17,18,19,20,23]$.

Study characteristics. We identified 44 articles published until January 2002 on the Gly972Arg polymorphism in Type 2 diabetic patients and control subjects. We excluded five studies because they examined the expression of the mutation instead of the prevalence $[29,30,31,32,33]$. We excluded seven studies because case subjects were relatives of Type 2 diabetic patients [34, 35, 36, 37] or were obese subjects [27, 38, 39] instead of Type 2 diabetic patients. An appropriate control group was missing in five studies [7, 40, 41, 42, 43], three studies did not provide clear data about prevalence rates $[44,45,46]$ and two studies were excluded because odds ratios could not be calculated [24, 25]. Of the 22 included publications (Fig. 1), five provided separate associations in different populations $[8$, $15,17,19,23]$. These associations were considered as separate studies.

Of the studies five were population-based studies $[5,8,19$, 21] and 22 studies were hospital-based studies [2, 3, 4, 6, 9, $10,11,12,13,14,15,16,17,18,20,22,23,26]$. Seventeen studies included Caucasian subjects $[2,3,4,5,8,11,12,14$, $15,18,19,20,22,23,26]$, eight studies included Asian subjects $[6,8,9,10,13,16,17]$, and three studies black or South American subjects [15, 21, 23] (Fig. 1). Diagnostic tests to exclude diabetes in the control subjects were a single fasting blood glucose test in ten studies [2, 3, 8, 14, 18, 19, 20, 21, 22] and a glucose tolerance test in nine studies $[5,6,8,9,10,16$, 
$17,23]$. In nine studies no diagnostic test has been used or reported $[4,11,12,13,15,23,26]$. SSCP analysis was used in three studies to determine the polymorphism [6, 15], fifteen studies used direct enzyme digestion $[8,10,12,14,16,17,18$, $19,20,21,22,26]$, and seven studies used both $[2,4,5,9,11$, 13, 23]. The method of analysis was not reported in three studies [3, 23].

Statistical analysis. To check for publication bias, a funnel plot was constructed. We examined funnel plot asymmetry visually and measured the degree of asymmetry using Egger's unweighted regression asymmetry test [47]. Studies were tested for Hardy-Weinberg equilibrium in the control group using Chi-square tests [48]. Summary odds ratios and corresponding 95\% CI were estimated by random effects meta-regression analysis using the STATA 7.0 statistical software package [49]. To explore reasons for observed heterogeneity, we carried out sensitivity analyses on study characteristics and tested their influences on the association between the Gly972Arg variant and prevalence of Type 2 diabetes. A $p$ value of 0.05 was considered statistically significant.

\section{Results}

Results from 27 studies with 3408 diabetic patients and 5419 non-related control subjects were included in this meta-analysis (Fig. 1). We could not identify heterogeneity visually (Fig. 2) or in terms of statistical significance $(p=0.15)$, indicating no publication bias.

The allele frequencies of the control group of one study [5] were not in Hardy-Weinberg equilibrium. Calculations were done with and without this study. As results were similar, this study was not excluded.

Odds ratios of Type 2 diabetes for carriers compared to non-carriers of the Gly972Arg variant ranged from 0.55 to 4.75 (Fig. 1). The summary odds ratio was 1.25 (95\% C.I. $1.05-1.48$ ). The average proportion of carriers was $8.6 \%$ in healthy control subjects and $11.4 \%$ in diabetic patients. The overall population attributable risk was $2.1 \%$.

We further examined if the association of the Gly972Arg variant with Type 2 diabetes did depend on ethnicity, type of study, or diagnostic test used to exclude diabetes presence, type of measurement of the polymorphism, prevalence of the polymorphism, and age of the cases. Heterogeneity was observed for type of study, diagnostic test used to exclude diabetes in the control subjects and age of the case subjects (Fig. 3).

The summary odds ratio was 0.98 (95\% C.I. 0.74-1.30) for population based studies, including 860 cases and 1,476 control subjects, compared with a summary odds ratio of 1.43 (95\% C.I. 1.17-1.74) for clinical based studies including 2,548 cases and 3,943 controls $(p=0.03)$. Studies using a glucose tolerance test to exclude diabetes showed a lower odds ratio compared with studies using a single fasting blood glucose test or no test at all $(p=0.03)$. The summary odds ratio decreased with age of cases $(p=0.03)$.

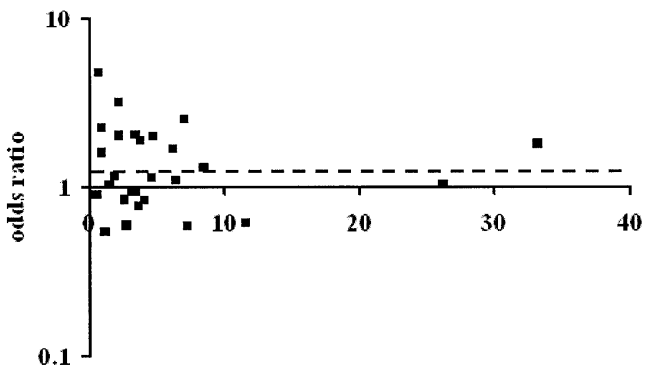

precision

Fig. 2. Funnel plot for subjects with the Arg-variant versus subjects without this variant, unadjusted. Interrupted and uninterrupted reference lines indicate no effect and total summary odds ratio, respectively

ETHNICTTY
Caucasian
Asian
TYPE OF STUDY
Clinical based
Population based
TEST IN CONTROLS
No test
Fasting glucose test
Glucose tolerance test
AGE OF CASES
$35-45$ yTs
$45-55$ yrs
$55-65$ yTs

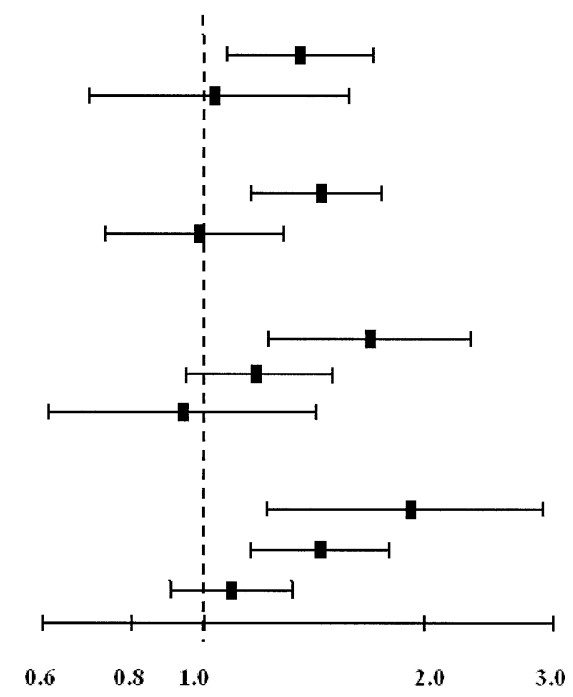

Fig. 3. Crude summary odds ratios for the Gly972Arg variant and prevalence of Type 2 diabetes by ethnicity, type of study, test in controls and age of cases

Based on the regression equation the OR reduced from 1.87 (95\% C.I. 1.24-2.82) for case subjects aged 35 to 45 years to 0.85 (95\% C.I. $0.59-1.24$ ) for case subjects that were 65 to 75 years old. The age of case subjects was lower in hospital-based studies compared with population-based studies $(54.9 \pm 6.4$ vs $65.2 \pm 8.2$ years; $p=0.045)$. There was no difference in the age of cases between studies that used a glucose tolerance

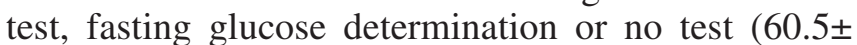
7.6, 55.4 $\pm 8.8,55.3 \pm 5.7$ years respectively, $p=0.36$ ). All population-based studies used a glucose tolerance test or fasting blood glucose determination to exclude diabetes among the control subjects. No test was done in six hospital-based studies. As the three modifiers (type of study, type of test to exclude diabetes, and age of case subjects) were highly interrelated it was not possible to assess the independent impact in the meta-regression analysis.

Although the odds ratio for studies with Caucasian subjects was slightly higher than that for studies with 
Asian subjects (Fig. 3), this difference was not statistically significant $(p=0.26)$. The prevalence of the polymorphism and the analytical method to detect the polymorphism did not change the summary odds ratios.

Additional information on BMI was retrieved for ten studies. The summary odds ratio for these studies was 1.14 (95\% C.I. 0.78-1.65). In studies with subjects with an average BMI greater than $27 \mathrm{~kg} / \mathrm{m}^{2}(395$ Type 2 diabetic subjects and 367 control subjects) or an average BMI less than or equal to $27 \mathrm{~kg} / \mathrm{m}^{2}(788$ diabetic patients and 1523 control subjects), no effect of the Arg-variant on the prevalence of Type 2 diabetes was found (OR 0.76 , 95\% C.I. $0.46-1.25$ and OR $1.2395 \%$ C.I. $0.75-2.01)$.

\section{Discussion}

Transfection studies with insulin receptor cells indicated that the Gly972Arg polymorphism of the IRS-1 gene impaired insulin-stimulated signalling [32]. A relationship between this polymorphism with the risk for Type 2 diabetes is therefore biologically plausible. Indeed, in our meta-analysis of 27 studies, including 3,408 diabetic patients and 5,419 control subjects, the summarized findings suggest an association between the presence of the Gly972Arg variant with Type 2 diabetes. In addition, several sources of heterogeneity between different studies were identified.

The summary odds ratio for population-based studies was lower than for hospital-based studies. This difference could be due to differences in phenotype. Cases detected in population-based studies include subjects with mild forms of diabetes, such as subjects newly diagnosed with diabetes after a single glucose tolerance test. Hospital-based studies generally include patients with more overt and symptomatic diabetes. These could be genetically different from those with newly diagnosed diabetes as individuals with milder glucose intolerance might not develop clinical or only at a high age [50]. Diabetes diagnosed at a younger age is thought to have a greater genetic predisposition [51]. We indeed observed an increasing odds ratio with a younger age of the case subjects. The age of case subjects was also lower in hospitalbased studies compared with population based studies. This suggests that related differences in phenotype of the diabetic patients could account for the observed heterogeneity between population-based and hospitalbased studies.

The difference in odds ratio found in populationbased studies and hospital-based studies could also be due to the type of test, that was used. All included population-based studies used a fasting glucose concentration or a glucose tolerance test to classify subjects as controls. Hospital-based studies did not consistently use one test: in fact different types of tests
(GTT, fasting or no test) were used evenly. Our results indicated that a more extensive test to detect diabetes in control subjects such as a glucose tolerance test resulted in a lower odds ratio. This could be due to the detection of a larger number of individuals with mild diabetes.

In general, a population-based design might be preferable in studies of non-related subjects as it is more likely that the control subjects are recruited from the same source population, avoiding selection bias [52]. This could be methodologically more sound compared to hospital-based studies with often only have a limited description of the control subjects and the selection process, leading to differential and nondifferential misclassification of the control subjects. Both population-and hospital-based association studies have been criticized, because population admixture could be a source of confounding [53]. Family-based studies have been advocated as the preferred design for detecting genetic associations, because they check for population stratification. However, others have shown that there is only a relatively small effect from population stratification in a well-designed population association study [54].

Only one family-based study on the Gly972Arg polymorphism and Type 2 diabetes has been reported to date [55]. No association was found, although there was a trend in the same direction (OR $1.1595 \%$ C.I. 0.71-2.03) as compared with our study. It is not clear from this study whether the results were different according to phenotype, because it included Type 2 diabetes patients as well as subjects with impaired glucose tolerance or a pre-diabetic state.

A major difficulty in identifying genes responsible for Type 2 diabetes is the definition of the phenotype [56]. This is also illustrated by the small population attributable risk of $2.1 \%$ in our study, due to the relatively low prevalence of the IRS-1 Arg972 variant. Since most individuals do not develop diabetes until later in life, a more appropriate phenotype might be insulin resistance or impaired insulin secretion. These metabolic abnormalities are identifiable even in the early stages of the natural history of Type 2 diabetes when glucose tolerance is normal. The Gly972Arg polymorphism has been associated with increased insulin resistance in obese subjects [27, 57, 58]. Human pancreatic islets from $\mathrm{Arg} 972$ carriers had reduced insulin content, altered insulin release, and a greater number of immature secretory granules [59]. As our results suggest that the IRS-1 Gly927Arg genotype is associated with a diabetes phenotype occurring at an earlier age, the importance of gene to gene interactions is also a matter that needs further elucidation [60].

In conclusion, this meta-analysis, including all available evidence to date, indicates that carriers of the $972 \mathrm{Arg}$ variant of the IRS-1 gene are at a $25 \%$ increased risk of having Type 2 diabetes compared with 
non-carriers, contributing to about $2 \%$ of the prevalence. The odds ratios are higher for hospital-based studies, including relatively young, symptomatic, cases. The contribution to specific subtypes of Type 2 diabetes could therefore be higher.

Acknowledgements. The study was supported by a grant from Netherlands Organization for Scientific Research, grant number 980-10-006, Nutrition and Chronic Diseases. We would like to thank all authors from whom we received additional information concerning BMI of the subjects. We thank Dr. H.C. Boshuizen from the National Institute of for Public Health and the Environment, Centre for Information Technology and Methodology, for statistical advice.

\section{References}

1. Gupta BBP (1997) Mechanism of insulin action. Current Sci 73:993-1003

2. Almind K (1993) Aminoacid polymorphisms of insulin receptor substrate-1 in non-insulin-dependent diabetes mellitus. Lancet 342:828-832

3. Hager J, Zouali H, Velho G, Froguel P (1993) Insulin receptor substrate-(IRS-1) gene polymorphisms in French NIDDM families. Lancet 342:1430

4. Imai Y, Fusco A, Suzuki Y et al. (1994) Variant sequences of insulin receptor substrate-1 in patients with noninsulindependent diabetes mellitus. J Clin Endocrinol Metab 79:1655-1658

5. Laakso M, Malkki M, Kekäläinen P, Kuusisto J, Deeb SS (1994) Insulin receptor substrate-1 variants in non-insulindependent diabetes. J Clin Invest 94:1141-1146

6. Shimokawa K, Kadowaki H, Sakura H et al. (1994) Molecular scanning of the glycogen synthase and insulin receptor substrate-1 genes in Japanese subjects with non-insulindependent diabetes mellitus. Biochem Biophys Res Commun 202:463-469

7. Grant PJ, Stickland MH, Mansfield MW (1995) Insulin receptor substrate-1 gene and cardiovascular risk factors in NIDDM. Lancet 346:841-842

8. Hitman GA, Hawrami K, McCarthy MI et al. (1995) Insulin receptor substrate-1 gene mutations in NIDDM; implications for the study of polygenic disease. Diabetologia 38:481-486

9. Mori H, Hashiramoto M, Kishimoto M, Kasuga M (1995) Amino acid polymorphisms of the insulin receptor substrate-1 in Japanese noninsulin-dependent diabetes mellitus. J Clin Endocrinol Metab 80:2822-2826

10. Chuang LM, Lai CS, Yeh JI, Wu HP, Tai TY, Lin BJ (1996) No association between the Gly971Arg variant of the insulin receptor substrate 1 gene and NIDDM in the Taiwanese population. Diabetes Care 19:446-449

11. Mammarella S, Esposito DL, Creati B et al. (1996) Mutational analysis of the insulin receptor substrate-1 in noninsulin dependent diabetes. Diabetologia 39:A75

12. Sigal RJ, Doria A, Warram JH, Krolewski AS (1996) Codon 972 polymorphism in the insulin receptor substrate-1 gene, obesity, and risk of noninsulin-dependent diabetes mellitus. J Clin Endocrinol Metab 81:1657-1659

13. Ura S, Araki E, Kishikawa H et al. (1996) Molecular scanning of the insulin receptor substrate-1 (IRS-1) gene in Japanese patients with NIDDM: identification of five novel polymorphisms. Diabetologia 39:600-608
14. Zhang Y, Stratton IM, Warren-Perry MG, Orho M, Groop L, Turner RC (1996) UKPDS 19: heterogeneity in NIDDM: separate contributions of IRS-1 and beta3-adrenergic-receptor mutations to insulin resistance and obesity respectively with no evidence for glycogen synthase gene mutations. Diabetologia 39:1505-1511

15. Panz VR, Raal FJ, O'Rahilly S, Kedda MA, Joffe BI (1997) Insulin receptor substrate-1 gene variants in lipoatrophic diabetes mellitus and non-insulin-dependent diabetes mellitus: a study of South African black and white subjects. Hum Genet 101:118-119

16. Lepretre F, Vionnet N, Budhan S et al. (1998) Genetic studies of polymorphisms in ten non-insulin-dependent diabetes mellitus candidate genes in Tamil Indians from Pondichery. Diabetes Metab 24:244-250

17. Yamada K, Yuan X, Ishiyama S et al. (1998) Codon 972 polymorphism of the insulin receptor substrate-1 gene in impaired glucose tolerance and late-onset NIDDM. Diabetes Care 21:753-756

18. Baroni MG, D’Andrea MP, Montali A et al. (1999) A common mutation of the insulin receptor substrate-1 gene is a risk factor for coronary artery disease. Arterioscler Thromb Vasc Biol 19:2975-2980

19. Hart LM 't, Stolk RP, Dekker JM et al. (1999) Prevalence of variants in candidate genes for type 2 diabetes mellitus in the Netherlands: the Rotterdam study and the Hoorn study. J Clin Endocrinol Metab 84:1002-1006

20. Ito K, Katsuki A, Furuta M et al. (1999) Insulin sensitivity is not affected by mutation of codon 972 of the human IRS-1 gene. Horm Res 52:230-234

21. Lei HH, Coresh J, Shuldiner AR, Boerwinkle E, Brancati FL (1999) Variants of the insulin receptor substrate-1 and fatty acid binding protein 2 genes and the risk of type 2 diabetes, obesity, and hyperinsulinemia in African-Americans: the atherosclerosis risk in communities study. Diabetes 48:1868-1872

22. Benecke H, Topak H, Muhlen A von zur, Schuppert F (2000) A study on the genetics of obesity: influence of polymorphisms of the beta-3-adrenergic receptor and insulin receptor substrate 1 in relation to weight loss, waist to hip ratio and frequencies of common cardiovascular risk factors. Exp Clin Endocrinol Diabetes 108:8692

23. Celi FS, Negri C, Tanner K et al. (2000) Molecular scanning for mutations in the insulin receptor substrate-1 (IRS-1) gene in mexican americans with type 2 diabetes mellitus. Diabetes Metab Res Rev 16:370-377

24. Celi FS, Silver K, Walston J, Knowler WC, Bogardus C, Shuldiner AR (1995) Lack of IRS-1 codon 513 and 972 polymorphism in Pima Indians. J Clin Endocrinol Metab 80:2827-2829

25. Zeng WM, Peng J, Wan XX, Chen SH, Song HP (2000) The mutation of insulin receptor substrate-1 gene in Chinese patients with non-insulin-dependent diabetes mellitus. Chin Med J 113:80-83

26. Rosskopf D, Frey U, Eckhardt S et al. (2000) Interaction of the $\mathrm{G}$ protein beta 3 subunit T825 allele and the IRS-1 Arg972 variant in type 2 diabetes. Eur J Med Res 5:484-490

27. Clausen JO, Hansen T, Bjørbaek C et al. (1995) Insulin resistance: interactions between obesity and a common variant of insulin receptor substrate-1. Lancet 346:397402

28. Zeegers MP, Tan FE, Goldbohm RA, Brandt PA van den (2001) Are coffee and tea consumption associated with urinary tract cancer risk? A systematic review and metaanalysis. Int J Epidemiol 30:353-362 
29. Porzio O, Federici M, Hribal ML et al. (1999) The gly972Arg amino acid polymorphism in IRS-1 impairs insulin secretion in pancreatic $\beta$ cells. J Clin Invest 104:357-364

30. Yoshimura R, Araki E, Ura S et al. (1997) Impact of natural IRS-1 mutations on insulin signals: mutations of IRS-1 in the PTB domain and near $\mathrm{SH} 2$ protein binding sites result in impaired function at different steps of IRS-1 signaling. Diabetes 46:929-936

31. Imai Y, Philippe N, Sesti G, Accili D, Taylor SI (1997) Expression of variant forms of insulin receptor substrate-1 identified in patients with noninsulin-dependent diabetes mellitus. J Clin Endocrinol Metab 82:4201-4207

32. Almind K, Inoue G, Pedersen O, Kahn RK (1996) A common amino acid polymorphism in insulin receptor substrate-1 causes impaired insulin signaling. J Clin Invest 97:2569-2575

33. Whitehead JP, Humphreys P, Krook A et al. (1998) Molecular scanning of the insulin receptor substrate 1 gene in subjects with severe insulin resistance. Diabetes 47

34. Koch M, Rett K, Volk A et al. (1999) Amino acid polymorphism Gly 972 Arg in IRS-1 is not associated to lower clamp-derived insulin sensitivity in young healthy first degree relatives of patients with type 2 diabetes. Exp Clin Endocrinol Diabetes 107:318-322

35. Armstrong M, Haldane F, Avery PJ et al. (1996) Relationship between insulin sensitivity and insulin receptor substrate-1 mutations in non-diabetic relatives of NIDDM families. Diabet Med 13:341-345

36. Carvalho E, Jansson PA, Axelsen M et al. (1999) Low cellular IRS 1 gene and protein expression predict insulin resistance and NIDDM. Faseb J 13:2173-2178

37. Rett K, Koch M, Volk A, Maerker E, Jacob S, Haering H-U (1998) codon 972 polymorphism of the IRS-1 gene is prevalent in offspring of subjects with type 2 diabetes without determining clamp-derived insulin action. Diabetes 47:393a

38. Clement K, Dina C, Basdevant A et al. (1999) A sib-pair analysis study of 15 candidate genes in French families with morbid obesity: indication for linkage with islet 1 locus on chromosome 5q. Diabetes 48:398-402

39. Krempler F, Hell E, Winkler C, Breban D, Patsch W (1998) Plasma leptin levels - interaction of obesity with a common variant of insulin receptor substrate-1. Arterioscler Thromb Vasc Biol 18:1686-1690

40. Ossei-Gerning N, Mansfield MW, Stickland MH, Grant PJ (1997) Insulin receptor substrate-1 gene polymorphism and cardiovascular risk in non-insulin dependent diabetes mellitus and patients undergoing coronary angiography. Clin Lab Haem 19:123-128

41. Armstrong M, Haldane F, Taylor RW, Alberti KGMM, Turnbull DM, Walker M (1996) Human insulin receptor substrate-1: variant sequences in familial non-insulin dependent diabetes mellitus. Diabet Med 13:133-138

42. Tagawa T, Yoshioka R, Kodama M, Sakamoto K, Watarai T, Yamasaki Y (1998) The characteristics of NIDDM patients with the codon-972 variant of IRS-1 gene. Diabetes 47:393a

43. Weisnagel SJ, Chagnon YC, Rankinen T et al. (2000) The insulin receptor substrate-1 (IRS-1) Gly972Arg polymorphism is associated with obesity in the Quebec Familiy study (QFS). Diabetes 49:822
44. Stern MP, Mitchell BD, Blangero J et al. (1996) Evidence for a major gene for type II diabetes and linkage analyses with selected candidate genes in Mexican-Americans. Diabetes 45:563-568

45. Delafontaine P (2000) IRS-1 variant: a new risk factor for coronary artery disease? [editorial; comment]. Arterioscler Thromb Vasc Biol 20:283-284

46. Hansen T, Hansen L, Reneland R et al. (1997) Hyperglycemia and obesity independently interact with the gly972arg variant of the insulin receptor substrate-1 to increase insulin resistance. Proc Gen Diab 35:1309

47. Egger M, Davey Smith G, Schneider M, Minder C (1997) Bias in meta-analysis detected by a simple, graphical test. BMJ 315:629-634

48. Schaid DJ, Jacobsen SJ (1999) Biased tests of association: comparing of allele frequencies when departing from Hardy-Weinberg proportions. Am J Epidemiol 149:706711

49. Statacorp (1999) Stata statistical software. Stata, College Station, Texas

50. Burke JP, Haffner SM, Gaskill SP, Williams KL, Stern MP (1998) Reversion from type 2 diabetes to nondiabetic status. Influence of the 1997 American Diabetes Association criteria. Diabetes Care 21:1266-1270

51. Owen K, Ayres S, Corbett S, Hattersley A (2002) Increased risk of diabetes in first-degree relatives of young-onset type 2 diabetic patients compared with relatives of those diagnosed later. Diabetes Care 25:636-637

52. Langholz B, Rothman N, Wacholder S, Thomas DC (1999) Cohort studies for characterizing measured genes. J Natl Cancer Inst Monogr 26:39-42

53. Altshuler D, Kruglyak L, Lander E (1998) Genetic polymorphisms and disease. N Engl J Med 338:1626

54. Wacholder S, Rothman N, Caporaso N (2000) Population stratification in epidemiologic studies of common genetic variants and cancer: quantification of bias. J Natl Cancer Inst 92:1151-1158

55. Altshuler D, Hirschhorn JN, Klannemark M et al. (2000) The common PPARgamma Pro12Ala polymorphism is associated with decreased risk of type 2 diabetes. Nat Genet 26:76-80

56. DeFronzo RA (1997) Pathogenesis of type 2 diabetes: Metabolic and molecular implications for identifying diabetes genes. Diabetes Rev 5:177-269

57. Jellema A, Feskens EJM, Mensink RP, Saris WHM, Kromhout D (2002) Cardiovascular risk markers in an overweight and normal weight population with oversampling of carriers of the IRS-1 972Arg variant (Abstract). Atherosclerosis 3 (Suppl 2):133

58. Baroni MG, Arca M, Sentinelli F et al. (2001) The G972R variant of the insulin receptor substrate-1 (IRS-1) gene, body fat distribution and insulin-resistance. Diabetologia 44:367-372

59. Marchetti P, Lupi R, Federici M et al. (2002) Insulin secretory function is impaired in isolated human islets carrying the $\mathrm{Gly}(972) \rightarrow$ Arg IRS-1 polymorphism. Diabetes 51:1419-1424

60. Saltiel AR, Kahn CR (2001) Insulin signalling and the regulation of glucose and lipid metabolism. Nature 414:799-806 